\title{
Análise da proximidade entre as questōes de Física do Enem e as novas orientações da BNCC para a Física no ensino médio
}

\author{
Alisson Cristian Giacomelli*, Filipe Serro Algeri**, Luiz Marcelo Darroz ${ }^{\star \star \star}$
}

\section{Resumo}

Neste trabalho, apresenta-se uma análise comparativa entre as novas orientações da Base Nacional Comum Curricular (BNCC) para a área de Ciências da Natureza e suas Tecnologias e as questões de Física encontradas nos anos de 2016, 2017 e 2018 na primeira aplicação da prova do Enem. Pesquisas anteriores relatam o ganho de importância dessa prova após passar a servir como forma de ingresso no ensino superior, mas também apontam tentativas falhas em contextualizar assuntos e em realizar a interdisciplinaridade. Com o advento da BNCC, surgiu a oportunidade de reavaliar a prova do Enem, a fim de compreender as tendências desta e prever adaptações para o cumprimento das novas orientações nacionais. Ao todo, foram avaliadas 40 questões de Física do Enem e 26 habilidades de três competências distintas da BNCC, na busca por correlações entre elas. De acordo com os resultados deste trabalho, a prova possui uma tendência conteudista, o que vai de encontro com a maior parte das habilidades da Base. Alguns assuntos da Física ainda precisam ser inseridos na prova. Na parte de contextualização e da interdisciplinaridade, as provas analisadas apresentam melhora em comparação com pesquisas anteriores. A Base traz uma preocupação grande com o conhecimento do método e do desenvolvimento da Ciência, além da capacidade de aplicação do método científico e de análise e difusão de informações científicas, sendo possível que futuras provas também reservem espaço para tais discussões.

Palavras-chaves: Enem; BNCC; Física; Ciências da Natureza e suas Tecnologias; Educação.

* Doutor em Educação pela UPF, Mestre em Ensino de Ciências e Matemática pela UPF, Especialista em Física pela UPF e Licenciado em Física pela UPF. Professor do curso de Física da UPF. E-mail: alissongiacomelli@upf.br

* Licenciado em Física pela UPF. E-mail: 159160@upf.br

*** Doutor em Educação em Ciências pela UFRGS, Mestre em Ensino de Física pela UFRGS, Especialista em Física pela UPF, Licenciado em Física pela UFSM, Licenciado em Matemática pela UPF, Docente permanente no programa de pós-graduação em Ensino de Ciências e Matemática - UPF, Docente permanente no programa de pós-graduação em Educação - UPF. Docente do curso de Física - UPF. E-mail: Idarroz@upf.br 


\section{Introdução}

Rosa e Rosa (2012) discutem que, durante o regime militar (entre 1964 e 1985), o ensino no Brasil foi marcado por um viés mais tecnicista, cujo objetivo primeiro era a preparação para o mercado de trabalho, em uma tentativa clara de estimular o desenvolvimento econômico nacional.

Com a devolução do poder político à sociedade civil, surge também a necessidade de alterar o modo de ensino, de adequar a educação aos valores desta nova sociedade. Nesse sentido, surge a Lei de Diretrizes e Bases (LDB), em 1996, que, dentre outras coisas, define os objetivos para o ensino médio:

I - a consolidação e o aprofundamento dos conhecimentos adquiridos no ensino fundamental, possibilitando o prosseguimento de estudos;

II - a preparação básica para o trabalho e a cidadania do educando, para continuar aprendendo, de modo a ser capaz de se adaptar com flexibilidade a novas condições de ocupação ou aperfeiçoamento posteriores;

III - o aprimoramento do educando como pessoa humana, incluindo a formação ética e o desenvolvimento da autonomia intelectual e do pensamento crítico;

IV - a compreensão dos fundamentos científico-tecnológicos dos processos produtivos, relacionando a teoria com a prática, no ensino de cada disciplina. (BRASIL, 1996, art. 35).

Logo em seguida, em 1998, foi criado o Exame Nacional do Ensino Médio (Enem), a fim de cumprir as determinações legais e avaliar o aprendizado ao término da educação básica, que deveria formar os estudantes para a vida em sociedade (SILVEIRA; BARBOSA; SILVA, 2015; MARCOM; KLEINKE, 2016).

No ano de 2009, o Enem foi reformulado, passando a servir de instrumento para ingresso no ensino superior, sendo forma única ou parcial de ingresso (HERNANDES; MARTINS, 2013). De acordo com Marcom e Kleinke (2016), milhões de candidatos disputam através do Enem vagas no ensino superior, seja através do Programa Universidade para Todos (ProUni), seja pelo Financiamento Estudantil (Fies), nas instituições privadas, seja através do Sistema de Seleção Unificada (SiSU) na esfera pública.

Tal mudança na função do Enem já produziu resultados pontuais. Peixoto e Linhares (2010) apontam uma maior abordagem de conteúdo de Física no novo Enem em comparação ao modelo de exame praticado antes da reformulação. Essa alteração na estrutura do exame deu-lhe crescente importância, fato que resultou 
na maior atenção de professores, estudantes e pesquisadores no que diz respeito à prova. Marcom e Kleinke (2016) destacam que possíveis erros nas questões foram buscados e explorados como nunca, apontando problemas na elaboração de questões contextualizadas.

Hernandes e Martins (2013) analisaram o caderno de Ciências da Natureza de cinco provas do Enem: a prova vazada em 2009, a prova aplicada em 2009, a primeira e a segunda aplicação em 2010 e a prova aplicada em 2011. Tal amostragem conta com setenta e duas questões envolvendo Física, e estas foram "inicialmente classificadas por Competência e Habilidade segundo a Matriz de Referência do Exame para a área de Ciências da Natureza" (HERNANDES; MARTINS, 2013, p. 63).

Após essa categorização primária, os autores propuseram agrupamento das questões por Competência, ainda de acordo com a Matriz, usando o método de análise do conteúdo de Bardin. O objetivo dessa etapa foi avaliar as questões e identificar as proximidades destas com os Parâmetros Curriculares Nacionais (PCN), com os Parâmetros Curriculares Nacionais do Ensino Médio (PCN+) e com as Orientações Curriculares para o Ensino Médio (OCEM), bem como a sugestão de orientações ao ensino de Física tendo o Enem como balizador (HERNANDES; MARTINS, 2013).

Ao término da pesquisa, Hernandes e Martins (2013, p. 81) concluem que as provas analisadas se aproximaram das orientações dos PCN e PCN+ em relação aos anos anteriores, mas ainda existe a presença de questões cujos contextos são desnecessários para a resolução. Ainda assim, os autores defendem que existe uma sinalização para a "Física das coisas" e que o Enem "pode se tornar, com o seu aprimoramento, um indutor da qualidade de ensino".

Por sua vez, Silveira, Stilck e Barbosa (2014, p. 473), depois de analisar as provas de 2012 e 2013, afirmam que “[...] no Enem, não existe uma prova de Física. Quinze questões de Física são encontradas, distribuídas ao acaso, entre as quarenta e cinco questões de Ciências da Natureza". Os autores prosseguem afirmando que o motivo dessa disposição é a tentativa de construir uma prova interdisciplinar. Para esses autores, a tentativa de alcançar a interdisciplinaridade é falha também ao realizar essa "distribuição ao acaso" das questões, pois são questões de disciplinas diferentes (Física, Química e Biologia) simplesmente misturadas em um caderno. Os pesquisadores chamam a atenção à não presença de questões de Física Moderna nas provas e ao excesso de questões de Mecânica, sendo 13 de um total de 30. 
Justamente esses fatos que orientam o que deve ser estudado nas escolas e o que é "irrelevante".

Silveira, Stilck e Barbosa (2014) ainda defendem que a qualidade das questões de Física é muito baixa, e isso decorre de todas serem contextualizadas o mais próximo possível do cotidiano, deixando margem enorme para "proposições esdrúxulas", e são dadas como péssimos exemplos as questões 85 do caderno azul de 2013 e a questão 77 do caderno azul de 2012. A questão 85 do caderno azul de 2013 apresenta inúmeras soluções possíveis por falta de clareza em seu enunciado, enquanto na questão 77 do caderno azul de 2012, são encontrados, no mínimo, quatro problemas envolvendo conceitos e clareza textual.

Observa-se que as críticas, ora mais ásperas, ora mais suaves, apontam a necessidade de revisão entre aquilo que é estabelecido legalmente e aquilo que é cobrado na prática. Essa necessidade ganha importância à medida que, de modo direto ou indireto, o Enem sinaliza para as escolas, cursos preparatórios e, principalmente, aos estudantes que anseiam adentrar no ensino superior, quais os assuntos a serem estudados com maior afinco. Além disso, a forma como as questões avaliativas são compostas nessa avaliação também seleciona métodos de ensino mais adequados para preparar os estudantes.

No ano de 2018, a promulgação da Base Nacional Comum Curricular (BNCC) trouxe novas dúvidas para estudantes e professores acerca de possíveis mudanças na estrutura da prova do Enem. De acordo com a BNCC, a área das Ciências da Natureza e suas Tecnologias, no ensino médio, deve proporcionar condições para que os alunos possam:

-Compreender e utilizar os conceitos e teorias que compõem a base do conhecimento científico-tecnológico, bem como os procedimentos metodológicos e suas lógicas;

-Conscientizar-se quanto à necessidade de continuar aprendendo e aprimorando seus conhecimentos;

-Apropriar-se das linguagens científicas e utilizá-las na comunicação e na disseminação desses conhecimentos; $\mathrm{e}$

-Apropriar-se das linguagens das tecnologias digitais e tornar-se fluentes em sua utilização. (BRASIL, 2018, p. 467).

Tendo isso em vista, é possível levantar alguns questionamentos: como as questões de Física dos últimos três anos se relacionam com as orientações da BNCC? Qual a proximidade entre aquilo que foi cobrado na prática e aquilo que é recomendado atualmente? Deve ser feita alguma mudança no formato da prova - em relação à 
Física - para adequá-la ao que reza a Base ou a prova já está de acordo? No caso de haver a necessidade de mudanças, em que sentido seriam?

Partindo desses questionamentos, o principal objetivo do presente estudo é analisar a proximidade entre as questões de Física dos anos de 2016, 2017 e 2018 com as novas orientações trazidas pela BNCC, prevendo possíveis mudanças na prova e tecendo críticas onde for necessário.

Nesse sentido, a próxima seção traz discussões sobre os aspectos metodológicos da pesquisa seguidos da categorização dos dados. Posteriormente, são explanados elementos relacionados à análise dos dados e, finalmente, tecem-se as considerações finais respectivas ao estudo.

\section{Metodologia}

O presente estudo corresponde a uma pesquisa bibliográfica de caráter exploratório, que, de acordo com Gil (2002, p. 41), possui como finalidade "proporcionar maior familiaridade com o problema, com vistas a torná-lo mais explícito ou constituir hipóteses". O estudo caracteriza-se como qualitativo, pois se faz uma comparação entre proximidade de conceitos, algo que não pode ser quantificado em números, mas entendido com significados (MINAYO, 2001).

A coleta dos cadernos de provas das Ciências da Natureza e suas Tecnologias foi realizada através da internet, no endereço eletrônico do INEP. As provas selecionadas foram relativas à primeira aplicação dos anos de 2016, 2017 e 2018, sendo todos os cadernos da cor azul. Destas provas, foram avaliadas apenas as questões de Física, sendo 14 questões na prova de 2016, 13 na prova de 2017 e 13 na prova de 2018 . Optou-se pelos cadernos de cor azul apenas por preferência dos pesquisadores, não havendo distinção entre o conteúdo deste caderno e os demais.

Por tratar-se de uma comparação com as novas orientações presentes na BNCC, as questões de Física estão categorizadas de acordo com as competências e habilidades definidas na própria base, disponíveis entre as páginas 554 e 560 do referido documento. Tais categorias possuem um sistema de identificação oficial, que será mantido. As categorias são identificadas pelo padrão EM13CNTXYY, onde X é referente às competências $(1,2$ ou 3$)$ e YY é referente às habilidades $(1,2,3 \ldots)$. Por exemplo, a habilidade 2 da competência 1 é dada por EM13CNT102. Ao todo, são 26 
habilidades, distribuídas do seguinte modo: 7 habilidades na primeira competência, 9 habilidades na segunda competência e 10 habilidades na terceira competência.

As competências e habilidades são transcritas da BNCC e, posteriormente, comentadas pelo autor, que se coloca na perspectiva de um professor de Física. É importante ressaltar essa informação, visto que as habilidades foram elaboradas para contemplar toda a área de Ciências da Natureza e a pesquisa limita-se em avaliar a partir de uma perspectiva relacionada à disciplina de Física.

Para a catalogação das questões, utilizou-se o seguinte sistema de identificação: cor do caderno, ano de aplicação, número da questão na prova. Por exemplo, a questão 74 da prova azul do ano de 2016 fica identificada como A16Q74: "A" representa a cor azul, " 16 " indica o ano de 2016 e "Q74" aponta a questão 74. Não se fez necessária a distinção entre as cores azul e amarelo para os cadernos, uma vez que todos os cadernos selecionados pertencem à cor azul.

\section{Categorização}

\section{Competência específica 1}

A competência específica 1 é definida do seguinte modo:

Analisar fenômenos naturais e processos tecnológicos, com base nas interações e relações entre matéria e energia, para propor ações individuais e coletivas que aperfeiçoem processos produtivos, minimizem impactos socioambientais e melhorem as condições de vida em âmbito local, regional e global. (BRASIL, 2018, p. 554).

Essa competência está subdividida em sete habilidades. A primeira habilidade é catalogada como EM13CNT101; segue sua transcrição:

Analisar e representar, com ou sem o uso de dispositivos e de aplicativos digitais específicos, as transformações e conservações em sistemas que envolvam quantidade de matéria, de energia e de movimento para realizar previsões sobre seus comportamentos em situações cotidianas e em processos produtivos que priorizem o desenvolvimento sustentável, o uso consciente dos recursos naturais e a preservação da vida em todas as suas formas. (BRASIL, 2018, p. 555).

Essa categoria pode ser entendida como geral e nisso abrange todas as questões analisadas, uma vez que a conservação e a transformação de energia estão presentes em toda a Física, em qualquer fenômeno. No entanto, optou-se por analisar por meio dessa categoria as questões que envolvem a área de Mecânica, uma vez que outras 
áreas da Física possuem categorias mais bem definidas e contemplam questões que estariam aqui classificadas de acordo com a interpretação generalista.

Questões classificadas: A16Q63, A16Q66, A16Q77, A16Q82, A17Q99, A17Q108, A17Q131, A18Q103, A18Q122, A18Q128, A18Q132, A18Q134.

Exemplos:

- A questão A17Q108 contextualiza uma criança brincando em uma cama elástica, a posição zero é definida na altura de equilíbrio da cama elástica. É necessário apontar o gráfico que melhor representa a relação da Energia Cinética com a Energia Potencial Elástica e Gravitacional de acordo com a posição da criança (altura).

- A questão A16Q77 ilustra o uso de trilhos de ar para estudar colisões de carrinhos. Uma tabela mostra a posição de dois carrinhos em determinados instantes e o estudante precisa estudar uma colisão inelástica para determinar a massa de um dos carrinhos.

- A questão A16Q66 apresenta um mecanismo de relógio por engrenagens através de uma imagem. Uma tabela contém o número de dentes de cada engrenagem. É dada a frequência do motor e deve-se calcular a frequência de giro do ponteiro.

- A questão A18Q104 dá imagens de cinco ferramentas (abridor de garrafas, alicate, carrinho de mão, pinça e quebra-nozes) e o aluno precisa indicar em qual delas a força potente é maior que a força resistente.

Segue a transcrição da segunda habilidade catalogada como EM13CNT102:

Realizar previsões, avaliar intervenções e/ou construir protótipos de sistemas térmicos que visem à sustentabilidade, considerando sua composição e os efeitos das variáveis termodinâmicas sobre seu funcionamento, considerando também o uso de tecnologias digitais que auxiliem no cálculo de estimativas e no apoio à construção dos protótipos. (BRASIL, 2018, p. 555).

Entende-se que essa habilidade se refere a fenômenos térmicos, tais como aquecimento e resfriamento, dilatação e contração, escalas termométricas, trocas de calor, mecanismos de troca de calor e a termodinâmica em geral.

Questões classificadas: A16Q54, A16Q84, A16Q86, A16Q88, A17Q127.

Exemplos:

- A questão A16Q84 faz comparações entre a sensação térmica ao encostar em uma bandeja de alumínio e em uma bandeja de plástico (ambas em 
equilíbrio térmico com o ambiente) e com a velocidade de derretimento de um cubo de gelo em cada bandeja.

- Aquestão A17Q127, por sua vez, apresenta um gráfico relacionando o aquecimento proporcionado por um chuveiro de acordo com a vazão de água e com o modo escolhido (morno, quente e superquente). O estudante dispõe também de informações como a tensão de funcionamento, a potência do modo superquente e o calor específico da água. É necessário relacionar a potência do modo morno com o modo superquente.

Segue a transcrição da terceira habilidade catalogada como EM13CNT103:

Utilizar o conhecimento sobre as radiações e suas origens para avaliar as potencialidades e os riscos de sua aplicação em equipamentos de uso cotidiano, na saúde, no ambiente, na indústria, na agricultura e na geração de energia elétrica. (BRASIL, 2018, p. 555).

Por radiações, o que costuma ser entendido (professores em geral, livros didáticos e portais de busca) são as ondas eletromagnéticas e a emissão de partículas. Nas questões observadas, encontram-se apenas referentes a ondas eletromagnéticas.

Questões classificadas: A16Q86, A17Q101, A17Q103, A17Q107, A18Q97, A18Q125, A18Q129.

Exemplos:

- Aquestão A16Q86 aborda o funcionamento do forno micro-ondas. A bandeja rotativa é tirada e substituída por outra que fica estática. Uma camada grossa de manteiga é colocada nessa bandeja. A questão apresenta o desenho da onda estacionária e nomeia numericamente os nós e os ventres. O estudante deve indicar duas posições da onda que provocam derretimento da manteiga.

- Aquestão A17Q107 explica o funcionamento da depilação a laser e apresenta um gráfico relacionando a absorção de diferentes comprimentos de onda pela melanina, pela água e pela oxi-hemoglobina. É necessário selecionar o comprimento de onda ideal para a depilação.

Segue a transcrição da quarta habilidade catalogada como EM13CNT104:

Avaliar os benefícios e os riscos à saúde e ao ambiente, considerando a composição, a toxicidade e a reatividade de diferentes materiais e produtos, como também o nível de exposição a eles, posicionando-se criticamente e propondo soluções individuais e/ ou coletivas para seus usos e descartes responsáveis. (BRASIL, 2018, p. 555). 
Essa habilidade está mais ligada à Química e à Biologia, principalmente à primeira, porém encontra-se uma questão de Física que se enquadra.

Questões classificadas: A17Q93.

Exemplo:

A questão A17Q93 explica o uso do polímero semicondutor polianilina para monitorar a concentração de amônia em granjas avícolas graças à propriedade que esse semicondutor possui de quadriplicar a sua resistência elétrica quando submetido a altas concentrações do gás tóxico. Cabe ao estudante calcular a resistência elétrica em condições normais através de um gráfico corrente $\mathrm{x}$ potencial e depois estimar tal grandeza na presença excessiva da amônia.

Segue a transcrição da quinta habilidade catalogada como EM13CNT105:

Analisar os ciclos biogeoquímicos e interpretar os efeitos de fenômenos naturais e da interferência humana sobre esses ciclos, para promover ações individuais e/ ou coletivas que minimizem consequências nocivas à vida. (BRASIL, 2018, p. 555).

Identificaram-se questões reportando efeitos da ação humana sobre ecossistemas e sobre os referidos ciclos, mas o tema em si é complexo, o que já justifica pouca ocorrência na prova.

Questões classificadas: A16Q54.

Exemplos:

- Aquestão A16Q54 mostra a necessidade do uso de água para o arrefecimento de uma usina de energia elétrica, destacando o cumprimento de normas de segurança naquilo que tange ao aumento de temperatura para a água devolvida ao rio. O objetivo dessa questão é calcular a vazão de água destinada ao arrefecimento dentro dos parâmetros legais.

Segue a transcrição da sexta habilidade catalogada como EM13CNT106:

Avaliar, com ou sem o uso de dispositivos e aplicativos digitais, tecnologias e possíveis soluções para as demandas que envolvem a geração, o transporte, a distribuição e o consumo de energia elétrica, considerando a disponibilidade de recursos, a eficiência energética, a relação custo/benefício, as características geográficas e ambientais, a produção de resíduos e os impactos socioambientais e culturais. (BRASIL, 2018, p. 555).

Nessa categoria, estão presentes todas as questões que abordam a produção, armazenagem, distribuição, consumo e impactos acerca da energia elétrica. 
Questões classificadas: A16Q47, A16Q54, A17Q105.

Exemplos:

- Aquestão A16Q47 explica a diferença entre a potência instalada e a potência teórica da hidrelétrica de Itaipu e pede ao aluno que calcule a potência não aproveitada pela usina.

- A questão A17Q105 explica e ilustra o funcionamento de uma usina híbrida eólica e de biogás, que usa o excesso de eletricidade proveniente da rotação das pás para provocar eletrólise da água e armazenar hidrogênio. Nos períodos de escassez de vento, o hidrogênio é misturado com biogás para gerar energia, sendo essa a relação que o estudante precisa identificar.

A sétima habilidade é catalogada como EM13CNT107; segue sua transcrição:

Realizar previsões qualitativas e quantitativas sobre o funcionamento de geradores, motores elétricos e seus componentes, bobinas, transformadores, pilhas, baterias e dispositivos eletrônicos, com base na análise dos processos de transformação e condução de energia envolvidos - com ou sem o uso de dispositivos e aplicativos digitais -, para propor ações que visem a sustentabilidade. (BRASIL, 2018, p. 555).

Nessa categoria, pelo seu tamanho, excluíram-se todas as questões colocadas na anterior. Foram selecionadas questões que abordam eletrostática, eletrodinâmica e eletromagnetismo.

Questões classificadas: A16Q55, A16Q59, A16Q74, A16Q86, A16Q88, A17Q93, A17Q110, A17Q127, A17Q129, A17Q133, A18Q97, A18Q108, A18Q112, A18Q115, A18Q120.

Exemplos:

- A questão A16Q74 mostra uma associação em paralelo de três lâmpadas iguais e nomeia alguns pontos ao longo do circuito. $\mathrm{O}$ estudante precisa identificar pontos nos quais as correntes são iguais.

- A questão A17Q133 é sobre conversão de energia mecânica em elétrica através do uso de espiras e ímãs. A questão deseja dobrar a tensão máxima do gerador, mas sem alterar o valor da corrente de curto e o estudante precisa indicar como fazê-lo.

- Aquestão A18Q112 explica brevemente o funcionamento da tecnologia Touch Screen com o uso de telas resistivas e apresenta uma ilustração. O objetivo dessa questão é calcular a resistência equivalente do circuito fechado ao clicar em uma posição dada da tela. 


\section{Competência específica 2}

A competência específica 2 é definida do seguinte modo:

Analisar e utilizar interpretações sobre a dinâmica da Vida, da Terra e do Cosmos para elaborar argumentos, realizar previsões sobre o funcionamento e a evolução dos seres vivos e do Universo, e fundamentar e defender decisões éticas e responsáveis. (BRASIL, 2018, p. 556).

Essa competência está subdividida em nove habilidades. A primeira habilidade é catalogada como EM13CNT201; segue sua transcrição:

Analisar e discutir modelos, teorias e leis propostos em diferentes épocas e culturas para comparar distintas explicações sobre o surgimento e a evolução da Vida, da Terra e do Universo com as teorias científicas aceitas atualmente. (BRASIL, 2018, p. 557).

Essa categoria, apesar de ser muito importante para a compreensão do desenvolvimento científico, não está presente na amostra recolhida. A questão A16Q82 menciona a descoberta das polias móveis na antiguidade, mas não diz nada sobre como ela era explicada; então, não é o bastante para aqui se enquadrar.

Questões classificadas: nenhuma.

A segunda habilidade é catalogada com EM13CNT202:

Analisar as diversas formas de manifestação da vida em seus diferentes níveis de organização, bem como as condições ambientais favoráveis e os fatores limitantes a elas, com ou sem o uso de dispositivos e aplicativos digitais (como softwares de simulação e de realidade virtual, entre outros). (BRASIL, 2018, p. 555).

Aqui, buscaram-se questões que apresentassem fenômenos físicos relacionados com manifestações da vida, seja em animais, seja em humanos.

Questões classificadas: A16Q57, A16Q54, A16Q88, A18Q115, A18Q129.

Exemplos:

- A questão A18Q115 dá a corrente e a tensão produzidas por um peixe amazônico em situações de perigo e deseja saber qual aparelho elétrico tem potência similar ao peixe.

- A questão A18Q129 explica brevemente como os humanos percebem as cores e pede para identificar como uma pessoa com Daltonismo perceberia dois comprimentos de ondas distintos, conforme gráfico disponibilizado. 
- A questão A16Q57 fala sobre a ecolocalização de morcegos através de pulsos ultrassônicos e o aluno precisa identificar como o morcego consegue detectar uma mariposa que se afasta dele.

A terceira habilidade é catalogada como EM13CNT203:

Avaliar e prever efeitos de intervenções nos ecossistemas, e seus impactos nos seres vivos e no corpo humano, com base nos mecanismos de manutenção da vida, nos ciclos da matéria e nas transformações e transferências de energia, utilizando representações e simulações sobre tais fatores, com ou sem o uso de dispositivos e aplicativos digitais (como softwares de simulação e de realidade virtual, entre outros). (BRASIL, 2018, p. 557).

Nessa categoria, estão presentes questões já classificas em outras, mas que pertencem a esta por tratarem de procedimentos médicos/estéticos em humanos e também de efeitos ambientais.

Questões classificadas: A16Q54, A16Q88, A17Q107.

Exemplos:

- A questão A16Q54 trata do arrefecimento de uma usina e já foi descrita anteriormente; está nessa categoria em razão da norma de segurança ambiental sobre a temperatura da água devolvida ao rio.

- A questão A16Q107 fala da depilação a laser, conforme já explicado previamente, mas cabe aqui também por explicar os critérios observados na escolha de uma onda adequada para a depilação com impactos colaterais mínimos.

- A questão A16Q88 apresenta o uso de magnetohipertermia para combater tumores, através do envio de nanopartículas magnéticas até as células tumorais e posterior aquecimento dessas células ao submeter as nanopartículas a um campo magnético alternado.

A quarta habilidade é catalogada como EM13CNT204:

Elaborar explicações, previsões e cálculos a respeito dos movimentos de objetos na Terra, no Sistema Solar e no Universo com base na análise das interações gravitacionais, com ou sem o uso de dispositivos e aplicativos digitais (como softwares de simulação e de realidade virtual, entre outros). (BRASIL, 2018, p. 557).

Essa categoria trata de assuntos relativos à astronomia e astrofísica, porém é comum aparecer sob o nome de "gravitação" em livros. Não há nenhuma questão referente a essa categoria.

Questões classificadas: nenhuma. 
A quinta habilidade é catalogada como EM13CNT205; segue sua transcrição:

Interpretar resultados e realizar previsões sobre atividades experimentais, fenômenos naturais e processos tecnológicos, com base nas noções de probabilidade e incerteza, reconhecendo os limites explicativos das ciências. (BRASIL, 2018, p. 557).

$\mathrm{Na}$ amostra selecionada, várias questões exigem interpretação de gráficos e tabelas, que se assemelham a resultados experimentais. Também, várias questões exigem previsões acerca de atividades experimentais, mas a noção de probabilidade e incerteza não aparece, está oculta, muito menos a noção de limites da validade de explicações científicas. Por esse motivo, não se classificou nenhuma questão nessa habilidade.

Questões classificadas: nenhuma.

A sexta habilidade é catalogada como EM13CNT206:

Discutir a importância da preservação e conservação da biodiversidade, considerando parâmetros qualitativos e quantitativos, e avaliar os efeitos da ação humana e das políticas ambientais para a garantia da sustentabilidade do planeta. (BRASIL, 2018, p. 557).

Nessa categoria, busca-se questões ou que mostrem estratégias de preservação ou que apontem diferentes peculiaridades de animais ou plantas, o que contribui para a percepção de que é importante preservar a biodiversidade e estudá-la.

Questões classificadas: A16Q54, A16Q57, A18Q115.

Exemplos:

- A questão A16Q54 é sobre o arrefecimento da usina (anteriormente citada) e contempla estratégias de preservação da biodiversidade aquática, através do controle da temperatura da água.

- A questão A16Q57 é sobre o peixe elétrico amazônico, mostrando manifestações curiosas e peculiares da vida.

A sétima habilidade é catalogada como EM13CNT207:

Identificar, analisar e discutir vulnerabilidades vinculadas às vivências e aos desafios contemporâneos aos quais as juventudes estão expostas, considerando os aspectos físico, psicoemocional e social, a fim de desenvolver e divulgar ações de prevenção e de promoção da saúde e do bem-estar. (BRASIL, 2018, p. 557).

Poderiam ser categorizadas questões que abordassem efeitos da luz azul dos aparelhos eletrônicos sob o ciclo circadiano ou problemas de postura em virtude de se passar muito tempo sentado, até relativas ao uso desregrado de agrotóxicos, 
no entanto, parece ser mais difícil haver alguma questão de Física, tendo em vista aquilo que é tradicionalmente ensinado e cobrado em provas.

Questões classificadas: nenhuma.

A oitava habilidade é catalogada como EM13CNT208:

Aplicar os princípios da evolução biológica para analisar a história humana, considerando sua origem, diversificação, dispersão pelo planeta e diferentes formas de interação com a natureza, valorizando e respeitando a diversidade étnica e cultural humana. (BRASIL, 2018, p. 557).

Essa categoria aparenta ser um campo interessante de trabalho para as Ciências, uma vez que propõe uma compreensão científica e racional sobre a diversidade de culturas e etnias humanas, porém não encontra representantes na amostra selecionada.

Questões classificadas: nenhuma.

A nona habilidade é catalogada como EM13CNT209; segue sua transcrição:

Analisar a evolução estelar associando-a aos modelos de origem e distribuição dos elementos químicos no Universo, compreendendo suas relações com as condições necessárias ao surgimento de sistemas solares e planetários, suas estruturas e composições e as possibilidades de existência de vida, utilizando representações e simulações, com ou sem o uso de dispositivos e aplicativos digitais (como softwares de simulação e de realidade virtual, entre outros). (BRASIL, 2018, p. 557).

Embora seja um tema interessante para o público em geral, questões acerca dele não se mostram comuns no Enem.

Questões classificadas: nenhuma.

\section{Competência específica 3}

A competência específica 3 é definida do seguinte modo:

Investigar situações-problema e avaliar aplicações do conhecimento científico e tecnológico e suas implicações no mundo, utilizando procedimentos e linguagens próprios das Ciências da Natureza, para propor soluções que considerem demandas locais, regionais e/ou globais, e comunicar suas descobertas e conclusões a públicos variados, em diversos contextos e por meio de diferentes mídias e tecnologias digitais de informação e comunicação (TDIC). (BRASIL, 2018, p. 558).

Essa competência está subdividida em dez habilidades:

A primeira habilidade é catalogada como EM13CNT301: 
Construir questões, elaborar hipóteses, previsões e estimativas, empregar instrumentos de medição e representar e interpretar modelos explicativos, dados e/ou resultados experimentais para construir, avaliar e justificar conclusões no enfrentamento de situações-problema sob uma perspectiva científica. (BRASIL, 2018, p. 559).

Entende-se que essa habilidade tem o intuito de introduzir estudantes ao método científico e habituá-los ao uso dele para enfrentar problemas. De um modo geral, o esperado é que todas as questões exijam essa habilidade por parte dos alunos. De um modo específico, não se encontrou nenhuma questão referente ao método científico em si.

Questões classificadas: nenhuma.

A segunda habilidade é catalogada como EM13CNT302; segue sua transcrição:

Comunicar, para públicos variados, em diversos contextos, resultados de análises, pesquisas e/ou experimentos, elaborando e/ou interpretando textos, gráficos, tabelas, símbolos, códigos, sistemas de classificação e equações, por meio de diferentes linguagens, mídias, tecnologias digitais de informação e comunicação (TDIC), de modo a participar e/ou promover debates em torno de temas científicos e/ou tecnológicos de relevância sociocultural e ambiental. (BRASIL, 2018, p. 559).

Entende-se que essa habilidade está mais relacionada com a divulgação do conhecimento científico por parte do estudante. Então, indiretamente, todas as questões da prova auxiliam, uma vez que permitem maior conhecimento por parte dos alunos. Mas de uma forma mais direta, não há nenhuma questão abordando estratégias de divulgação ou algo nesse sentido.

Questões classificadas: nenhuma.

A terceira habilidade é catalogada como EM13CNT303; segue sua transcrição:

Interpretar textos de divulgação científica que tratem de temáticas das Ciências da Natureza, disponíveis em diferentes mídias, considerando a apresentação dos dados, tanto na forma de textos como em equações, gráficos e/ou tabelas, a consistência dos argumentos e a coerência das conclusões, visando construir estratégias de seleção de fontes confiáveis de informações. (BRASIL, 2018, p. 559).

Compreende-se que essa habilidade é destinada a capacitar os alunos a analisar notícias e estudos científicos, bem como a confiabilidade das informações. De certa forma, é um complemento à habilidade anterior, mas também não está diretamente presente nas questões analisadas.

Questões classificadas: nenhuma.

A quarta habilidade é catalogada como EM13CNT304; segue sua transcrição: 
Analisar e debater situações controversas sobre a aplicação de conhecimentos da área de Ciências da Natureza (tais como tecnologias do DNA, tratamentos com células-tronco, neurotecnologias, produção de tecnologias de defesa, estratégias de controle de pragas, entre outros), com base em argumentos consistentes, legais, éticos e responsáveis, distinguindo diferentes pontos de vista. (BRASIL, 2018, p. 559).

Entende-se que essa habilidade se refere a temas nos quais a ética e a ciência encontram divergências, com o objetivo de capacitar o estudante ao uso de argumentos objetivos, claros e lógicos para participar de tais debates.

Questões classificadas: nenhuma.

A quinta habilidade é catalogada como EM13CNT305; segue sua transcrição:

Investigar e discutir o uso indevido de conhecimentos das Ciências da Natureza na justificativa de processos de discriminação, segregação e privação de direitos individuais e coletivos, em diferentes contextos sociais e históricos, para promover a equidade e o respeito à diversidade. (BRASIL, 2018, p. 559).

Entende-se que essa habilidade surge para combater aquilo que aconteceu. A título de exemplo, durante o regime nazista, cientistas afirmavam a supremacia da raça ariana e usavam isso para justificar crimes contra outros povos e outras etnias.

Questões classificadas: nenhuma.

A sexta habilidade é catalogada como EM13CNT306; segue sua transcrição:

Avaliar os riscos envolvidos em atividades cotidianas, aplicando conhecimentos das Ciências da Natureza, para justificar o uso de equipamentos e recursos, bem como comportamentos de segurança, visando à integridade física, individual e coletiva, e socioambiental, podendo fazer uso de dispositivos e aplicativos digitais que viabilizem a estruturação de simulações de tais riscos. (BRASIL, 2018, p. 559).

Nessa categoria, buscam-se questões que apontem riscos ou justifiquem medidas de segurança em atividades cotidianas (seja na vida comum, seja no ambiente de trabalho).

Questões classificadas: A16Q63, A17Q93, A17Q99, A17Q129, A17Q131, A18Q122.

Exemplos:

- A questão A18Q122 trabalha com os efeitos de alterar o tamanho das rodas em veículos, alertando para a mudança na estabilidade e também na alteração da relação entre a velocidade indicada no velocímetro e a velocidade real do veículo. 
- A questão A17Q129 comenta sobre o uso de cercas elétricas como medida de segurança e o aluno precisa calcular a relação entre a resistência interna do gerador e de uma pessoa para que o choque elétrico dessa cerca não seja fatal.

- A questão A17Q131 ilustra a diferença entre a distância percorrida em uma frenagem de emergência entre um motorista atento e um motorista desatento (que mexia no telefone celular enquanto dirigia).

A sétima habilidade é catalogada como EM13CNT307; segue sua transcrição:

Analisar as propriedades dos materiais para avaliar a adequação de seu uso em diferentes aplicações (industriais, cotidianas, arquitetônicas ou tecnológicas) e/ ou propor soluções seguras e sustentáveis considerando seu contexto local e cotidiano. (BRASIL, 2018, p. 559).

Entende-se que essa habilidade é de viés mais técnico, o que torna mais acessível na formulação de questões, conforme se vê nos exemplos.

Questões classificadas: A17Q93, A17Q101, A17Q103, A17Q110, A18Q112. Exemplos:

- A questão A17Q101 apresenta a comparação entre o espectro de emissão de cinco diferentes lâmpadas e o estudante precisa selecionar qual delas é mais adequada para iluminar uma sala com o melhor conforto ambiental.

- Aquestão A17Q103 mostra um gráfico representando a perda da intensidade de sinais em fibras ópticas para que o aluno defina qual a maior distância que um sinal pode percorrer nessa fibra óptica.

A oitava habilidade é catalogada como EM13CNT308; segue sua transcrição:

Investigar e analisar o funcionamento de equipamentos elétricos e/ou eletrônicos e sistemas de automação para compreender as tecnologias contemporâneas e avaliar seus impactos sociais, culturais e ambientais. (BRASIL, 2018, p. 560).

Nessa categoria, buscam-se questões que mostrem impactos causados nas atividades humanas por sistemas de automação. Trata-se de um tema muito rico, mas pouco explorado na amostra selecionada.

Questões classificadas: A18Q97.

Exemplos:

- A questão A18Q97 apresenta o uso de etiquetas de comunicação RFID para rastrear gado, vagões de trem, bagagens aéreas e veículos, e o aluno precisa apontar o princípio que permite o funcionamento de um modelo dado na 
questão. Trata-se de um sistema de localização automatizado, que dispensa a presença e fiscalização físicas constantes.

A nona habilidade é catalogada como EM13CNT309; segue sua transcrição:

Analisar questões socioambientais, políticas e econômicas relativas à dependência do mundo atual em relação aos recursos não renováveis e discutir a necessidade de introdução de alternativas e novas tecnologias energéticas e de materiais, comparando diferentes tipos de motores e processos de produção de novos materiais. (BRASIL, 2018, p. 560).

Entende-se que essa habilidade deseja capacitar o aluno a compreender relações políticas e econômicas orientadas na demanda energética e adoção de fontes cada vez mais renováveis e cada vez mais econômicas.

Questões classificadas: A17Q105.

Exemplos:

- A questão A17Q105, já descrita anteriormente, explica e ilustra a associação de geração de energia por meios eólicos e através da queima de biogás. É categorizada, pois mostra o esforço em desenvolver fontes alternativas para a geração de energia elétrica.

A décima habilidade é catalogada como EM13CNT310; segue sua transcrição:

Investigar e analisar os efeitos de programas de infraestrutura e demais serviços básicos (saneamento, energia elétrica, transporte, telecomunicações, cobertura vacinal, atendimento primário à saúde e produção de alimentos, entre outros) e identificar necessidades locais e/ou regionais em relação a esses serviços, a fim de avaliar e/ou promover ações que contribuam para a melhoria na qualidade de vida e nas condições de saúde da população. (BRASIL, 2018, p. 560).

Entende-se que essa habilidade tem o intuito de instigar o aluno a usar seus conhecimentos sobre as ciências da natureza para compreender os projetos e construções de infraestrutra e serviços básicos, compreendendo as demandas da sociedade ao seu entorno. Trata-se de outra habilidade riquíssima, mas com pouco aproveitamento dentro da amostra selecionada, talvez em virtude da dificuldade em traduzir em tal habilidade em questões para o exame.

Questões classificadas: A16Q54.

Exemplos:

- A questão A16Q54, sobre o arrefecimento da usina, é categoriza nessa habilidade pelo motivo de mostrar um dos efeitos da construção de usinas. 


\section{Discussão dos resultados}

Conforme apresentado na introdução, o Enem tem como objetivo avaliar a aprendizagem na educação básica e a BNCC traz novas orientações para o ensino básico. Assim, após a promulgação da BNCC, as provas do Enem deveriam desenvolver um processo de aproximação com as orientações contidas na BNCC. Algumas habilidades contidas na BNCC permitem a melhor conversão em questões do estilo lápis-papel, mas outras habilidades extrapolam esse estilo e não aparecem na prova.

As habilidades EM13CNT201, EM13CNT205, EM13CNT207, EM13CNT208, EM13CNT301, EM13CNT302, EM13CNT303, EM13CNT304 e EM13CNT305 abordam temas acerca do conhecimento e do método científico, da divulgação e análise de confiabilidade, do uso do saber científico para debater e analisar problemas complexos. Esses temas pouco - quando nada recorrentes - se mostraram na prova, talvez pela complexidade e/ou dificuldade desses assuntos gerarem exercícios do tipo lápis e papel. Todavia, destacamos a importância de tais discussões em sala de aula em nível básico, principalmente para que se alcance uma maior compreensão de como a Ciência se desenvolve e como o método científico é aplicado.

Dentre as competências específicas, a primeira é a que melhor está representada nas provas. Analisando de modo geral, a competência específica 1 é a de viés mais conteudista, o que parece facilitar a geração de questões referentes a ela. A disciplina de Física parece se adaptar muito bem a ela, o que é facilmente percebido pela quantidade de questões presentes em categorias como EM13CNT101, EM13CNT102, EM13CNT103 e em EM13CNT107; optar-se pelo critério mais genérico apresentado nessa primeira contemplaria todas as questões estudadas. Além disso, todas as habilidades contidas na primeira competência estão representadas na amostra selecionada, mesmo que de forma mais tímida em EM13CNT104 e EM13CNT105. Pela descrição destas, entende-se que favorecem disciplinas de Química e de Biologia, mas também há espaço para elos interdisciplinares da área do conhecimento em estudo. 
No entanto, partes da Física aparentemente ficam prejudicadas na BNCC, como a Hidrostática e a Hidrodinâmica, a Ondulatória e a Física Quântica e até, talvez, a Óptica, cuja presença está mais ligada à Óptica Física, que foi categorizada com a EM13CNT103. Poderia alegar-se que a habilidade EM13CNT101 englobaria tudo, adotando sua interpretação generalista, mas percebe-se que vários ramos da Física foram delimitados nessa competência em detrimento desses supracitados. A competência específica 2 é a menos contemplada nas provas do Enem, visto que apenas três das nove habilidades encontram questões correspondentes.

As habilidades EM13CNT204 e EM13CNT209 pertencem aos conteúdos de Astronomia, Gravitação e Cosmologia, sendo favoráveis para o trabalho em sala de aula e temas, em geral, populares entre os alunos e a sociedade. Nos anos analisados, nenhuma questão do Enem estava relacionada a esses temas.

Sobre as habilidades EM13CNT202, EM13CNT203 e EM13CNT206: trata-se justamente de áreas de integração entre as disciplinas da área da natureza, fato que favorece a formulação de questões, seja a fim de contextualização, seja a fim de difusão de informação. Além disso, apresentam boa taxa de correspondência com questões da prova.

As categorias EM13CNT306 e EM13CNT307 estão muito bem representadas no Enem. Além de contextualizar as questões, elas dão valor real à Física no cotidiano e nos processos produtivos. As habilidades EM13CNT308, EM13CNT309 e EM13CNT310 possuem campo para expansão, principalmente a EM13CNT308, visto a relação que possui com a habilidade EM13CNT107, que foi muito bem representada.

A seguir, é apresentada uma tabela relacionando as competências e habilidades com as questões correspondentes: 


\begin{tabular}{|c|c|c|}
\hline Competência & Habilidade & Questões \\
\hline \multirow{7}{*}{ Competência 1} & EM13CNT101 & $\begin{array}{l}\text { A16Q63, A16Q66, A16Q77, A16Q82, A17Q99, A17Q108, } \\
\text { A17Q131, A18Q103, A18Q122, A18Q128, A18Q132, } \\
\text { A18Q134. }\end{array}$ \\
\hline & EM13CNT102 & A16Q54, A16Q84, A16Q86, A16Q88, A17Q127. \\
\hline & EM13CNT103 & $\begin{array}{l}\text { A16Q86, A17Q101, A17Q103, A17Q107, A18Q97, A18Q125, } \\
\text { A18Q129. }\end{array}$ \\
\hline & EM13CNT104 & A17Q93. \\
\hline & EM13CNT105 & A16Q54. \\
\hline & EM13CNT106 & A16Q47, A16Q54, A17Q105. \\
\hline & EM13CNT107 & $\begin{array}{l}\text { A16Q55, A16Q59, A16Q74, A16Q86, A16Q88, A17Q93, } \\
\text { A17Q110, A17Q127, A17Q129, A17Q133, A18Q97, A18Q108, } \\
\text { A18Q112, A18Q115, A18Q120. }\end{array}$ \\
\hline \multirow{9}{*}{ Competência 2} & EM13CNT201 & --- \\
\hline & EM13CNT202 & A16Q57, A16Q54, A16Q88, A18Q115, A18Q129. \\
\hline & EM13CNT203 & A16Q54, A16Q88, A17Q107. \\
\hline & EM13CNT204 & ---- \\
\hline & EM13CNT205 & --- \\
\hline & EM13CNT206 & A16Q54, A16Q57, A18Q115. \\
\hline & EM13CNT207 & ---- \\
\hline & EM13CNT208 & ---- \\
\hline & EM13CNT209 & ---- \\
\hline \multirow{10}{*}{ Competência 3} & EM13CNT301 & ---- \\
\hline & EM13CNT302 & --- \\
\hline & EM13CNT303 & ---- \\
\hline & EM13CNT304 & ---- \\
\hline & EM13CNT305 & ---- \\
\hline & EM13CNT306 & A16Q63, A17Q93, A17Q99, A17Q129, A17Q131, A18Q122. \\
\hline & EM13CNT307 & A17Q93, A17Q101, A17Q103, A17Q110, A18Q112. \\
\hline & EM13CNT308 & A18Q97. \\
\hline & EM13CNT309 & A17Q105. \\
\hline & EM13CNT310 & A16Q54. \\
\hline
\end{tabular}




\section{Considerações finais}

De um modo geral, existe uma aproximação forte entre os Enem's anteriores e as novas recomendações da BNCC nas habilidades em que são valorizados conteúdos e aplicações do conhecimento científico. Pelo observado, a tendência da prova é manter esse viés, o que coloca a prova bem próxima da Base nesse aspecto.

Tendo esse fato em vista, existe um forte compromisso, quase que obrigação, de os assuntos de Astronomia, Gravitação e Cosmologia serem abordados nas próximas provas, uma vez não estão presentes não só em uma, mas, sim, duas habilidades da BNCC. As habilidades EM13CNT204 e EM13CNT209, relacionadas a essas temáticas, nada se diferenciam das habilidades contidas na competência específica 1, por exemplo, o que torna injustificada a dicotomia de representatividade entre estas na prova.

A área de Física Moderna também pode ser mais bem aproveitada, principalmente agora em que computadores quânticos estão sendo pesquisados e seguidamente aparecem na mídia. A falta de questões relacionadas a essa área da Física evidenciada nesta pesquisa vai de encontro com a pesquisa realizada por Silveira, Stilck e Barbosa (2014), em que foram analisadas as provas de 2012 e 2013. Tal carência é alvo de críticas pelos autores, cabendo destacar que, de acordo com o presente estudo, parece não ter ocorrido uma evolução significativa nesse aspecto.

Conforme visto nas pesquisas de Hernandes e Martins (2013), a preocupação por contextualizar a Física no cotidiano e nas ferramentas tecnológicas já é antiga e mostra seus resultados, tanto que não figuram mais, pelo menos de modo aparente, aberrações como aquelas denunciadas por Silveira, Stilck e Barbosa (2014), fato que revela uma evolução no padrão de composição da prova.

Todavia, a prova ainda traz muitas falhas no que diz respeito à interdisciplinaridade e, principalmente, quanto às habilidades relacionadas com a natureza da ciência e com a história da ciência, o que pode tornar precário o processo de alfabetização científica dos estudantes. 


\section{Analysis of the proximity between Enem's Physics questions and BNCC's new guidelines for Physics in high school}

\section{Abstract}

In this work, a comparative analysis is presented between the new guidelines of the National Common Curricular Base (BNCC) for the area of Natural Sciences and its Technologies and the Physics questions found in the years 2016, 2017 and 2018 in the first application of the test of Enem. Previous research reports the gain of importance of this test after starting to serve as a way of entering higher education, but also point out failed attempts to contextualize subjects and to achieve interdisciplinarity. With the advent of BNCC, the opportunity arose to reevaluate the Enem test, in order to understand its trends and provide for adaptations to comply with the new national guidelines. Altogether, 40 Enem Physics questions and 26 skills from three different BNCC competencies were evaluated, in the search for correlations between them. According to the results of this work, the test has a contentious tendency, which is in line with most of the skills of the Base. Some subjects of Physics still need to be inserted in the test. In terms of contextualization and interdisciplinarity, the evidence analyzed has improved compared to previous research. The Base brings a great concern with the knowledge of the method and the development of Science, in addition to the ability to apply the scientific method and to analyze and disseminate scientific information, and it is possible that future tests also reserve space for such discussions.

Keywords: Enem; BNCC; Physics; Natural Sciences and its Technologies; education.

\section{Referências}

BRASIL. Ministério da Educação. Lei no 9.394, de 20/12 / 1996. Estabelece as Diretrizes e Bases da Educação Nacional. Disponível em: <http://www.planalto.gov.br/ccivil_03/leis/L9394.htm>. Acesso em: 4 ago. 2019.

Base Nacional Comum Curricular. Disponível em: <http://basenacionalcomum.mec.gov. br/images/BNCC_EI_EF_110518_versaofinal_site.pdf> Acesso em: 4 ago. 2019.

. Enem: provas e gabaritos. Disponível em: <http://portal.inep.gov.br/provas-e-gabaritos>. Acesso em: 5 ago. 2019.

FAVERO, Altair Alberto; GABOARDI, Antonio; CENCI, Angelo (Coord.). Apresentação de trabalhos científicos: normas e orientações práticas. 5. ed. Passo Fundo: Ed. da UPF, 2014.

GIL, Antonio Carlos. Como elaborar projetos de pesquisa. 4. ed. São Paulo: Atlas, 2002.

HERNANDES, Jesusney Silva; MARTINS, Maria Inês. Categorização de questões de Física do novo ENEM. Caderno Brasileiro de Ensino de Física, v. 30, n. 1, p. 58-83, 15 abr. 2013.

MARCOM, Guilherme Stecca; KLEINKE, Maurício Urban. Análises dos distratores das questões de Física em Exames de Larga Escala. Caderno Brasileiro de Ensino de Física, v. 33, n. 1, p. 72-91, 25 abr. 2016.

MINAYO, Maria Cecília de Souza (Org.). Pesquisa social: teoria, método e criatividade. Petrópolis: Vozes, 2001. 
ROSA, Cleci Werner da; ROSA, Álvaro Becker da. O ensino de ciências (Física) no Brasil: da história às novas orientações educacionais. Revista Ibero-americana de Educação, n. 58, 2012.

SILVEIRA, Fernando Lang da; BARBOSA, Marcia Cristina Bernardes; SILVA, Roberto da. Exame Nacional do Ensino Médio (ENEM): uma análise crítica. Revista Brasileira de Ensino de Física, v. 37, n. 1, p. 1-5, mar. 2015.

SILVEIRA, Fernando Lang da; STILCK, Jürgen; BARBOSA, Marcia. Manifesto sobre a qualidade das questões de Física na Prova de Ciências da Natureza no Exame Nacional de Ensino Médio. Caderno Brasileiro de Ensino de Física, v. 31, n. 2, p. 473-479, 9 jul. 2014.

PEIXOTO, K. C. Q. da C.; LINHARES, M. P. Novo Enem: o que mudou? Uma investigação dos conceitos de Física abordados no exame. In: ENCONTRO DE PESQUISA EM ENSINO DE FÍSICA, 12, 2010, Águas de Lindóia. Anais... Águas de Lindóia: Sociedade Brasileira de Física, 2010. Disponível em: <https://sec.sbfisica.org.br/eventos/epef/xii/sys/resumos/T0058-1.pdf>. 